\title{
MJN HEALTH CARE SYSTEM ANALYSIS THROUGH WORK PERFORMANCE PREDICTIONS
}

\author{
Noemi B. Yntig \\ Faculty of Nursing, Cebu Normal University, Philippines \\ CorrespondenceEmail:noemay521@gmail.com
}

\begin{abstract}
Performance indicators are a popular mechanism for measuring the quality of healthcare to facilitate both quality improvement and systems management. The objective of this study is to analyse the health care system through work performance predictions among nurses globally. The researcher utilized a quantitative methodology by using artificial intelligence analysis. Data was collected through data mining analysis to identify patterns of relationship that existed between the variables and to measure the strength of the relationship, which in the case influence the age, staff adequacy, patient load, years of experience and types of working unit between the work performances of the nurses. The study employed a quantitative methodology by using artificial intelligence. The results indicate that age shows no dependence between the work performances, in increase staff adequacy is not consistent related to positive result in work performance as well as result in patient load. However, the years of experience shows significant relationship between working performance resulting in decrease work performance of employees. There was a sudden peak in work performance which was associate to a better result in the work performance. The researcher revealed that with some brief prospects, the health care system needs to realize the importance of good working environment for maximizing the level of job performance. This study concluded that the work performance is a key indicator which plays an important role for the success of any healthcare system. This contribute significantly to the overall healthcare of the world. The performance, therefore, has a great impact on quality and efficiency of healthcare. Hence, the researcher emphasized the importance of continuous monitoring and evaluation, as essential for an organization to motivate their employees to work hard for achieving the organizational goals and objectives.
\end{abstract}

Keywords: Healthcare Analysis, Performance predictions, Staff adequacy, Patient load

\section{INTRODUCTION}

Many hospital administrations fail to understand the importance of working environment for employee job satisfaction and thus face a lot of difficulties during their work. Such organizations are internally weak therefore unable to introduce innovative promotion into the market to outshine their competitors (Aiken, Clarke \& Sloane, 2002). Employees are essential component in the process of achieving the mission and vision of an organization. Employees should meet the performance criteria set by the organization to ensure the quality of their work. To meet the standards of organization, employees need a working environment that allows them to work freely without problems that may restrain them from performing up to the level of their full potential. The objective of this research paper is to analyse the impact of working environment on employee job satisfaction.

In predicting job performance, Vroom, (1964) proposes that performance is a multiplicative function of ability and motivation. However, at an earlier point Vroom clearly describes that "motivation as the force to choose high effort over low effort. In the context of predicting performance" this seems to be a reasonable assumption. A person puts forth a high degree of effort and has high ability then the person is a high performer. Conversely, if an individual put forth a great deal of effort but has no real ability, he should be a very low performer. Therefore, most tests of Vroom's model have attempted to account for choices among levels of effort. Even though there is value in understanding the factors which determine individual expenditure of effort, 
defining motivation as the force to choose high effort creates two important conceptual problems, neither of which have been clearly recognized.

The performance and efficiency of health workers play an important role for the success of any healthcare system that contribute significantly to the overall healthcare of the world. The performance, therefore, has a great impact on quality and efficiency of healthcare. In the modern era, organizations are facing several challenges due to the dynamic nature of the environment. One of the many challenges for a health care system is to satisfy its employees in order to cope up with the ever changing and evolving environment and to achieve success and remain in competition. In order to increase efficiency, effectiveness, productivity and job commitment of employees, the health care management must satisfy the needs of its employees by providing good working conditions. Bakotic \& Babic (2013) stated that for the workers who work under difficult working conditions revealed that it is a significant factor for job satisfaction, so workers under adverse working conditions are discontented.

Human resources are important as hospital indicator for success of effective and efficient utilization. Resources with enough quantity, high quality and professionally in accordance with the functions and duties are desirable. Empirical facts were showed that there are still a lot of errors and omissions that often occur in performing the duties of health services in hospitals, especially among nursing officer. Negligence of nursing practice of the nurse does not use the skill level and knowledge of nursing were not used when they are treating patients. Donald (2007) stated that access to resources and self-development is basically a recognition of the competence of human resources by introducing the theory and concept of KSEA (Knowledge, Skill, Experience, Attitude). Hence selfdevelopment of human beings observed or seen from four-sided viewpoint, namely the Integration of Knowledge and the views of academic abilities, skills gained from training, work experience based on length of service, and attitude based on the mastery of work.

The working environment has direct influence on job satisfaction and employee performance. Although these factors are important, unfortunately many companies pay less attention. For example the problem of temperature in the workplace, the space of workplace, job security, work equipment, relationships among employees and relationship with superiors (Castillo \& Cano, 2014). According to Sedarmayanti (200) the type of working environment is divided into two part: physical working environment and nonphysical working environment. Leadership is the process to influence the activities of individuals or groups in order to achieve the goals. Robbins \& Coulter (2007) state transformational leader inspires his followers and put aside their personal interests for the good of the organization and they can have a tremendous influence on the self- followers. The uniqueness and originality of this study include combined with the variable competence, working environment and transformational leadership as variables that influence job performance.

According to Pawirosumarto, Sarjana \& Gunawan, (2017), work environment is a whole infrastructure that exists around employees who are doing the work itself. The working environment includes: the workplace, the facilities and the tools of work, cleanliness, lighting, tranquility as well as the relationship between the people in the area. The type of work environment is divided into two, namely as physical working environment and nonphysical working environment. The working environment is all the intangible factors and being around a work area, generally affect the implementation of the employee's job. The working environment can be viewed form the two aspects: The internal environment, which is a factor in the organization that creates the cultural values and social venue for activities towards the destination. The external environment as an environment that generally reflect the strength of which is outside the organization.

In the modern era, organizations are facing several challenges due to the dynamic nature of the environment. Benefit society by encouraging nurses to contribute more to the jobs and may help them in their personal growth and development. Hence, it is essential for an organization to motivate their employees to work hard for achieving the organizational goals and objectives (Raziqa \& Maulabakhsh, 2015). Objective: the main objective of this study was to determine the effect of working environment on the performance of health care providers.

The working environment consists of two broader dimensions such as work and context. Work includes all the different characteristics of the job like the way job is carried out and completed, involving the tasks like task 
activities training, control on one's own job related activities, a sense of achievement from work, variety in tasks and the intrinsic value for a task. Results have shown that there is a positive link between work environment and intrinsic aspect of the job performance. Further the second dimension of job performance known as profile of the respondent such as age and length of service. This context comprises of the physical working conditions and the social working conditions (Sousa-Poza \& Sousa-Poza, 2011; Gazioglu \& Tanselb, 2014; Skalli, Spector 2013). It was observed that most management ignore the working environment within their organization resulting in an adverse effect on the performance of their employees. Working environment consists of safety to employees, job security, good relations with co-workers, recognition for good performance, motivation for performing well and participation in the decision-making process of the firm. Moreover once employees realize that the firm considers them important, they will have high level of commitment and a sense of ownership for their organization(Baah \& Amoako, 2011).

Different factors within the working environment such as staff adequacy, patient load, and types of working experience may affect job performance. Furthermore, top management limits employees to the tasks rather than creating a sense of responsibility among them by making them work in teams to attain high performance. Patterson, Warr \& West (2004) argues that the interaction between employees within a business is crucial for accomplishing the organizational goals. Further the communication of information must be properly done in a timely manner so that the operations of the business are running smoothly. If there is a clash between co-workers, then it is difficult to achieve the objectives of organization. Based on the above discussion, the objective of this paper is to determine the relationship between the working environment and employee job satisfaction.

Chandrasekhar (2011) argue that an organization needs to pay attention to create a work environment that enhances the ability of employees to become more productive in order to increase profits for organization. $\mathrm{He}$ also argued that human to human interactions and relations are playing more dominant role in the overall job satisfaction rather than money. Whereas management skills, time and energy, all are needed to improve the overall performance of the organization in the current era.

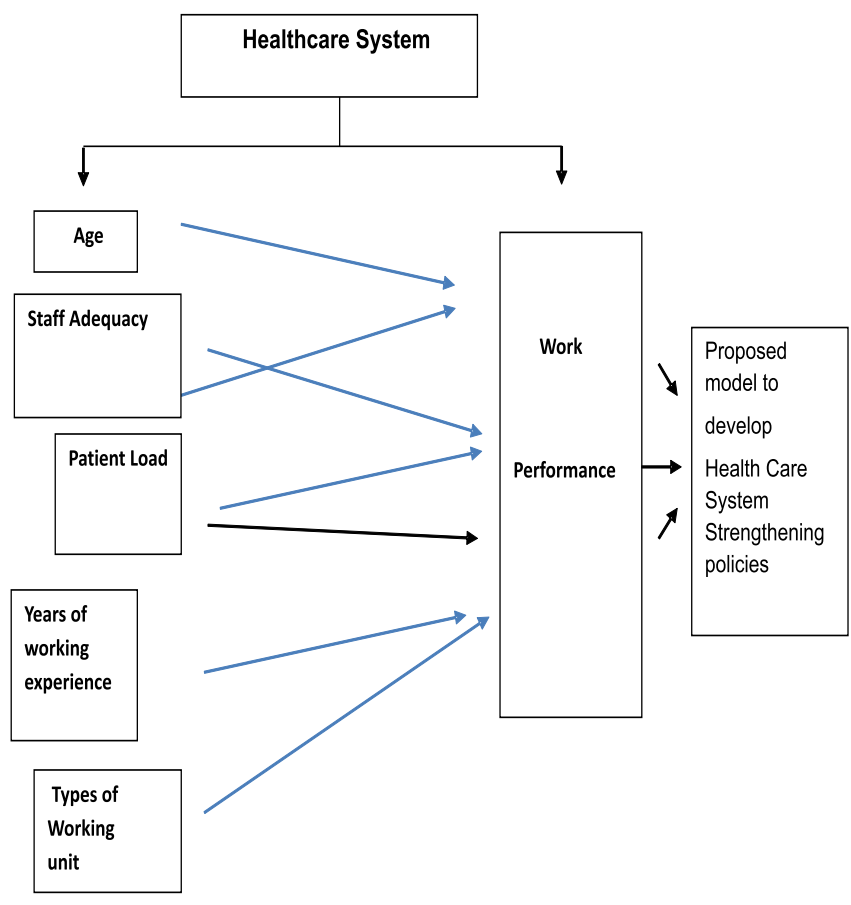

Figure 1: A conceptual model of Healthcare System Analysis Through Work Performance Predictions

This conceptual framework tries to explain how the variables includes the age, staff adequacy, patient load, years of working experience, and types of working unit influences health workers performance. This will aid to analyze the efficiency of healthcare system through work performance predictions and further findings can be proposed to develop healthcare system strengthening policies.

\section{Problem statement}

This study investigated and analyzed the individual's age profile and working environment that affect the healthcare system through work performance predictions. Specifically, it sought to answer the following inquiries: Does employee's age and working environment such as age of the employee, patient load, staff adequacy, years of working experience effects on performance level of health care providers and influences health care system?

\section{METHODOLOGY}

The research methodology is a quantitative method using artificial analysis to determine the relationship between the $(\mathrm{Y})$ independent variable on the $(\mathrm{X})$ dependent variable, to analyze the patterns of 
relationships between the staff adequacy, patient load, type of working unit, years of work experience as well as the age of the employee and the work performance of the nurses globally.

Data were obtained through the process of data mining both in local and international. It was run 100 times and analyzed through artificial intelligence. The results were interpreted which may further help the management to review existing motivational policies and practices with a hope that they can enhance between the work environment and work performance among the nurses. The purposes of the analysis are to identify weaknesses, variances, and any series of events that could cause the system to fail; and prioritize the identified problems for redesign.

\section{RESULTS AND DISCUSSION}

The purposes of the analysis are to identify weaknesses, variances, and any series of events that could cause the system to fail; and prioritize the identified problems for redesign and development of the healthcare system policies.

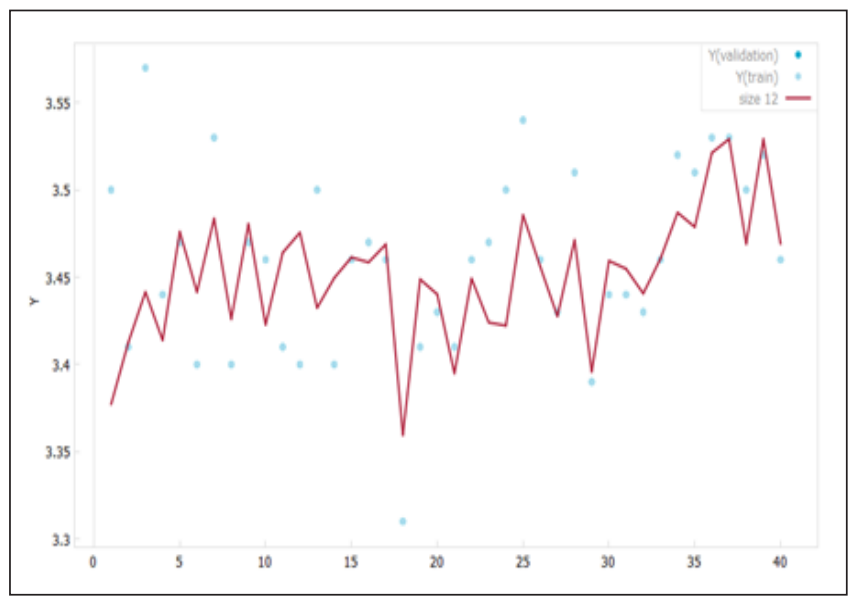

Figure 2: Result of relationship between age and work performance

120.759"Y=3.45100036783868- 0.00131108816329974*X*cos(1.999779739 $80719 * X) "$

The relationship between age and work performance is shown in Figure 2: The solution gives a trigonometric fit trend (see equation 1). The result shows no dependence between the two variables, thus fluctuating. Work performance, therefore, is not affected by age.
Results have shown that the age profile of the respondents indicate no dependence between the work performance meaning will not affect the dimension of work performance of the nurses.

According to Lammentakanen (2013), a crucial challenge for nursing management is to balance the needs of nurses of different ages and enable the use of all the options currently available for Continuing Professional Development (CPD) in health care organizations. Nurse Managers need to consider also opportunities for workplace learning when they allocate nursing resources in their units.

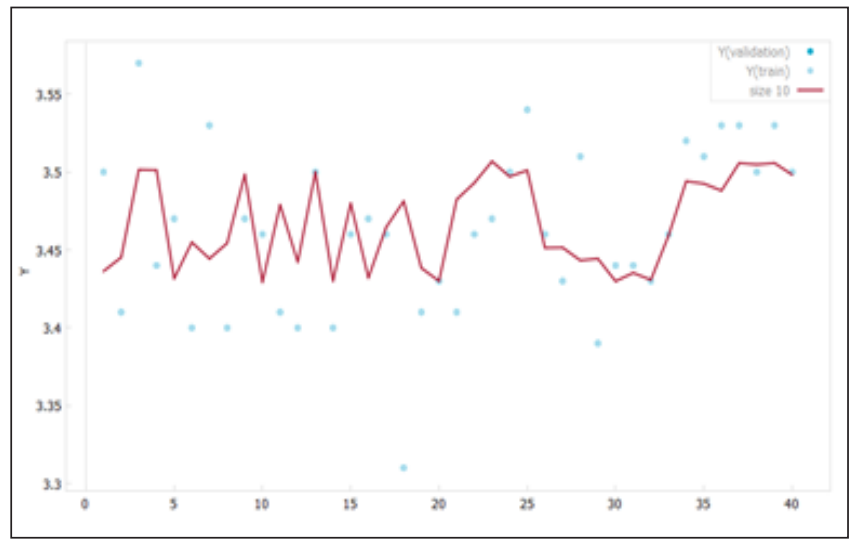

Figure 3: Relationship between staff adequacy and job performance.

$100.843 " Y=3.468072030563+0.0387999878028618 * \cos (3.519837320867$ $38 * X)$ "

The relationship between staff adequacy and job performance is shown in Figure 3: The solution gives a trigonometric fit trend (see equation 2). Increasing the staff adequacy does not show a consistent increase in the work performance. Therefore, there is no direct relationship between the two variables.

The increase and decrease of staff adequacy do not put a positive result in work performance as well. Allocation of patient load in Nursing is a critical factor in determining the quality of care in hospitals and the nature of patient outcomes but did not show consistent significant relationship because as the average length of stay for patients decreased then subsequently as the number of staffed beds also declines, hospitals begin to redesigning their systems of care, scheduling practices, and approaches to the care of hospitalized patients, in order to accommodate this decreased need. 


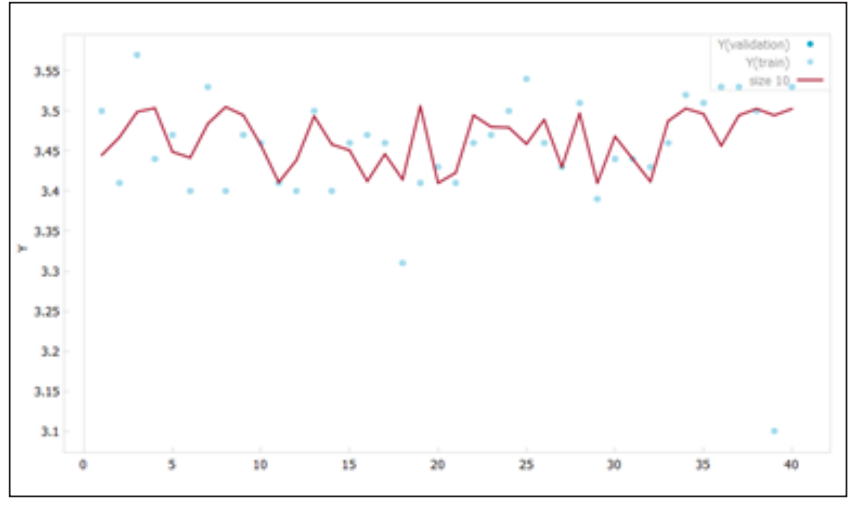

Figure 4: Relationship between patient load and work performance

$100.877 " \mathrm{Y}=3.45796206935312+0.0481242502942368 * \cos$ $(7.29847038908157 * X)$ "

The relationship between patient load and work performance is shown in Figure 4: The solution gives a trigonometric fit trend (see equation 3 ). The results show a random data. This nonlinearity proves that there is no direct relationship between patient load and its effect to work performance.

However, the years of experience shows significant relationship between working performance resulting in decrease of employee's work performance.

Hospitals pursue different goals at the same time: excellent service to their patients, good quality care, operational excellence, retaining employees. This requires a good balance between patient needs and nursing staff. One way to ensure a proper fit between patient needs and nursing staff is to work with a workload management method.

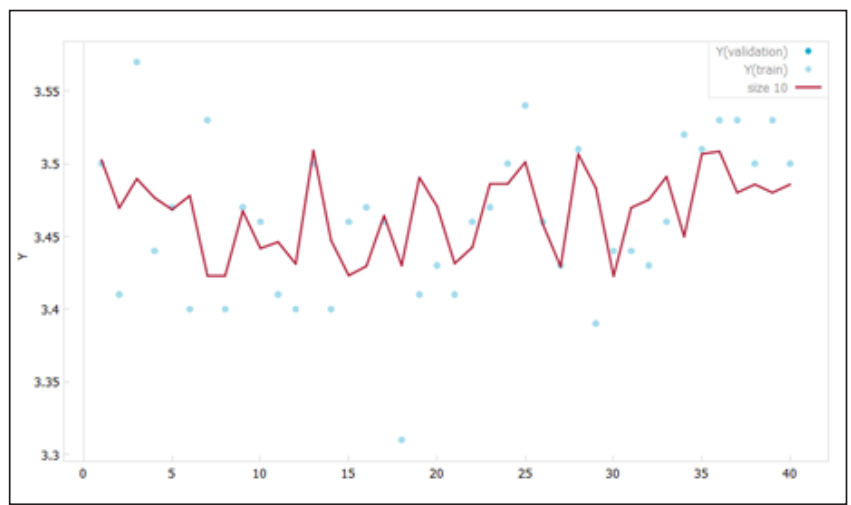

Figure 5: Relationship between years of working experience and work performance

$100.839 " \mathrm{Y}=3.46602060909971-0.0434753817607964 * \cos (-$ $25.7280542967607 * X) "$
The relationship between years of working experience and work performance is shown in Figure 5: The solution gives a trigonometric fit trend (see equation 4). The graph shows a random data. In the first part of the plot, few years of working experience result to a decrease in the work performance. The result shows decrease of years of experience revealed decrease in work performance.

Along its vertical axis the figure shows the deviation in actual and predicted work performance. Predicted years of experience is obtained through a linear regression where years of experience is the dependent variable and the predicted variables is the work performance. These explanatory or predicted variables are the main determinants of healthcare system analysis. The graph shows that with increase numbers of years of experience will greatly affect and decrease the level of performance of the nurses in the hospital. The horizontal axis shows the deviation of the predicted work performance. Predicted work performance obtained through a linear regression where working experience is the dependent variable, and the explanatory variable is working performance.

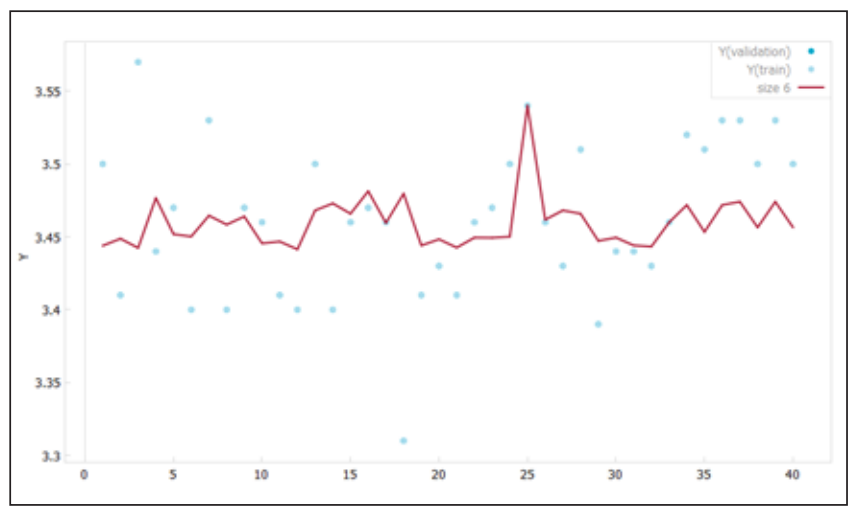

Figure 6: Relationship between types of working unit and work performance

60.916" $\mathrm{Y}=3.43941797752093+0.100658325467542 / \mathrm{x}^{\prime \prime}$

The relationship between types of working unit and work performance is shown in Figure 6: The fit trend of the result is presented in equation 5 . A sudden increase or peak in the work performance can be shown in the graph between 25 and 30 of the working type. This can be associated to a better result in the work performance.

There was a sudden peak in the types of working unit that can be associated to a better result in the work 
performance. The high variability in the relationship between performance and types of working unit revealed that there is a strong relationship between these two variables.

\section{CONCLUSION}

The work performance is influenced by various factors that are generally categorized under individual's profile and working environment. Specific factors under each category affect the level of performance. However, it was found out in the study the mean level predictors under the high frequency and sudden peak graph has a great influence to increase level of performance among nurses but there are certain domains that it would not affect the work performance. The study also revealed that the significant predictive variables for healthcare system analysis include years of experience and types of working unit. Therefore, the work performance is key indicator that plays an important role for the success of any healthcare system that contributes significantly to the overall healthcare of the world. The performance, hence, has a great impact on quality and efficiency of healthcare. However, the health care system need to realize the importance of good working environment for maximizing the level of job performance of the nurses.

\section{Conflict of Interests}

The author declares that they have no conflict of interest.

\section{ACKNOWLEDGEMENT}

The author is thankful to the institutional authority for completion of the work.

\section{REFERENCES}

Aiken, L., Clarke, S. \& Sloane, D. (2002). Hospital staffing, organizational support and quality of care: cross-national findings. International Journal for Quality in Health Care, 50(5), pp 87-94.

Baah, K. \& Amoako, G. K. (2011). Application of Frederick Herzberg's Two-Factor Theory in Assessing and Understanding Employee Motivation at Work: a Ghanaian Perspective. European Journal of Business and Management, 3(9), pp 1-8.

Bakotic, D. \& Babic, T.B. (2013). Relationship between Working Conditions and Job Satisfaction: The Case of Croatian Shipbuilding Company. International Journal of Business and Social Science, 4(2), pp 206-213.

Castillo, J.X. \& Cano, J. (2014). Factors Explaining Job Satisfaction Among Faculty. Journal of Agricultural Education, 45(3), pp 65-74.

Chandrasekar, K. (2011). Workplace Environment and Its Impact Organizational Performance in Public Sector organizations. International Journal of Enterprise Computing and Business Systems, 1(1), pp 1-19.

Chandrasekar, K. (2011). Workplace Environment and Its Impact Organizational Performance in Public Sector organizations. International Journal of Enterprise Computing and Business Systems, 1(1), pp 1-19.

Donald, M.T. (2007). Competence of Personal in Prospective Theories. Retrived from: http://www. journalh umanr esource management.com.id.

Gazioglu, S. \& Tanselb, A. (2006). Job satisfaction in Britain: individual and job related factors. Applied Economics, 38(10), pp 1163-1171.

Lammintakanen, J. (2013). Continuing professional development in nursing: does age matter (Department of Health and Social Management, University of Eastern Finland, Kuopio, Finland).

Pawirosumarto, S., Sarjana, P.K. \& Gunawan, R. (2017). The effect of work environment, leadership style, and organizational culture towards job satisfaction and its implication towards employee performance in Parador Hotels and Resorts, Indonesia. International Journal of Law and Management, 59(6), pp 1337-1358.

Petterson, I. (1998). Psychological stressors and well-being in health careworkers: the impact of an intervention program. Social Science and Medicine, 47(11), pp 1763-72. 
Raziq, A. \& Maula-bakhsh, R. (2014). The Impact of Working Environment on Job Satisfaction. Procedia Economics and Finance, 23, pp 717-725.

Robbins, S. P. \& Coulter, M. (2007). Management. $9^{\text {th }}$ edition. London: Prentice- Hall Sedarmayanti. (2009). Sumber Daya Manusia dan Produktivitas Kerja. Jakarta: Manju Mundur.

Skalli, A., Theodossiou, I. \& Vasileiou, E. (2008). Job as Lancaster Goods: facets of job satisfaction and overall job satisfaction. The Journal of Socio-Economics, 37(5), pp 1906-1920.

Sousa-Poza, A. \& Sousa-Posa, A. (2000). Taking another look at the gender/job-satisfaction paradox. International Review of Social Science, 53(2), pp 135-152.

Vroom, V. (1964). Work and motivation. New York Wiley. 